\title{
Hope at last for crisis-ridden Gauteng academic hospitals?
}

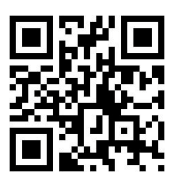

A national pilot scheme aims to give power back to clinicians and hospital managers, unraveling the crisis of mismanagement, poor planning and endemic corruption that has long compromised and even prevented healthcare delivery at Johannesburg's top tertiary hospitals.

The pilot turnaround strategy will begin with the embattled Gauteng health department, and ultimately aims to correct the ongoing dysfunction and often-woeful healthcare delivery at tertiary hospitals countrywide. It will be facilitated by Professor Adam Habib, the new Vice Chancellor of the University of the Witwatersrand (Wits), who was hand-picked by a deeply concerned national health minister, $\mathrm{Dr}$ Aaron Motsoaledi. Motsoaledi has also instructed Gauteng's warring parties - hospital CEOs and managers, clinical chiefs, provincial MEC Hope Papo and Premier Nomvula Mokonyane - to 'work together to clean up'.

The province's tertiary hospitals have lurched from one crisis to another. Previous turnaround strategies hardly made an impact as doctors fought in vain for vital life-saving equipment and/or its repair and maintenance, basic drugs and consumables and sufficient human resources to treat patients. Meanwhile potentially incendiary disputes, such as the conflict over the Remunerative Work Outside the Public Service (RWOPS) programme, soured relationships between hospital staff and provincial government even further and accelerated consultant resignations.

\section{What's wrong}

In previous probes by Izindaba, Gauteng's tertiary hospital doctors blamed 'turnstile' health MECs (politically responsible only to their provincial premier), poorly qualified hospital CEOs (financially held hostage to the infamously bureaucratic Gauteng Shared Service Centre (GSSC), responsible for all departments' procurement and payment) and evidence of major financial mismanagement by the province (e.g. the 2009/10 Auditor General's disclaimer that they were unable to verify the accuracy and authenticity of R19 billion in transactions). The lack of clear and transparent financial systems, as required by the Public Finance Management Act, generally makes it easier

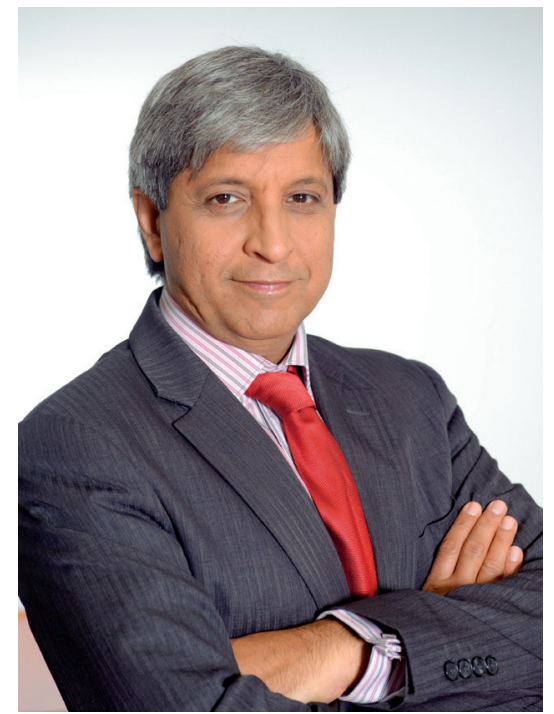

Turnaround 'point man' Professor Adam Habib, University of the Witwatersrand Vice-Chancellor.

to disguise endemic corruption, theft and waste. All parties Izindaba interviewed blamed much of the wastage on legitimate or semi-legitimate 'middlemen', who push up prices or actually steal from hospital consignments, including food destined for patients.

Professor Yasmien Jeenah is Clinical Head of Psychiatry and Chief of the Medical/ Clinical Advisory Committee at Chris Hani Baragwanath Academic Hospital, where she has worked for 13 years. She cited the lack of procurement as the biggest headache. '[We need] medication and lots of essential equipment. It's not just major equipment but basic things like syringes and needles, bandages and food. We serve socioeconomically compromised people. They ask me how they can take their medication at home when there's no food on the table - but how about when they're sick in hospital and we can't provide them with food? Some drugs actually make you hungry. I've never seen things as bad. Staff morale has certainly never been worse.'

Jeenah diplomatically described senior management as 'having patches of competency'. However, she believes that, as the first intervention directly led by and involving Wits University and the top national health leadership, the pilot project is 'great, and well overdue.' She added: 'It can't be an "us and them" scenario. Everyone must truly buy in.'
In agreement is Professor Martin Smith, Chief of Surgery and a 12-year veteran at Chris Hani Baragwanath, and new Head of Surgery at the Wits Medical School. He said at least two features distinguish this 'turnaround' from previous failures, which left clinicians very cynical. 'Firstly, Wits comes out very strongly in support of its medical staff, acknowledging the threats to its mandate of training and research and that it cannot be silent on service failure. Secondly, provincial government has had to very quickly come up with some model of management that addresses our concerns, not just the current focus on procurement of drugs and equipment but human resources and a whole host of other currently unworkable systems so this is quite exciting.'

Pointing out that service platform dysfunction leads to teaching platform dysfunction, Smith said that in future clinicians and hospital CEOs will be allowed to take more responsibility for their working environment. However, he warned strongly that managers would 'need to allow them to take that space', which would amount to a major change in operational culture.

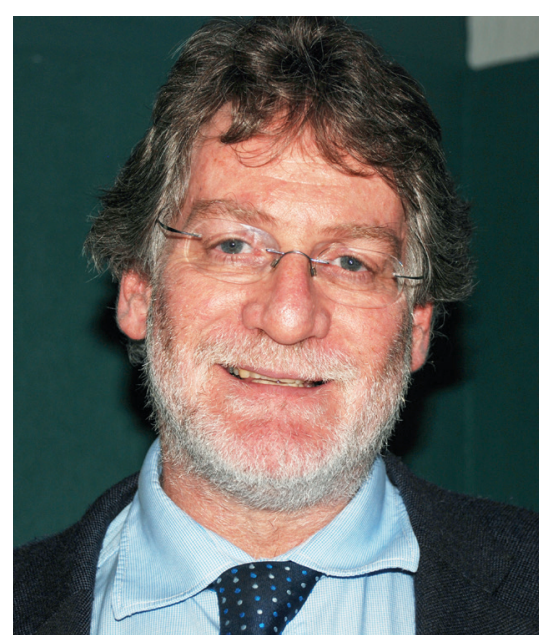

Professor Martin Smith, Chief of Surgery at Chris Hani Baragwanath Academic Hospital and new Head of Surgery at the Wits Medical School.

\section{What's right}

Habib and Professor Mac Lukhele, Head of the School of Clinical Medicine at Wits, confirmed that all parties had signed a 'developmental accord' that included the following immediate actions:

- A full $70 \%$ of essential stock previously procured via the GSSC will be delivered 
directly from service providers to Gauteng's four tertiary hospitals.

- At the time of writing, Dr Terence Carter, Deputy Director-General: Hospitals Tertiary Service and Workforce Management, had fully briefed all managers and clinicians to prevent misunderstanding of what the new systems are.

- Clinicians will have unprecedented input into the budgets and procurement processes that directly affect them, and will monitor their progress.

- Hospital CEOs will have ring-fenced budgets that empower them to set realistic ceilings on major equipment procurement. (In contrast, in mid-2011, the ceiling was set at R25 000 by a province desperately trying to manage a runaway budget.)

- There will be a minimum of 3 months' worth of stock of all vital equipment and consumables (now referred to as nonnegotiable stock items), with relevant managers held directly responsible for compliance. All stock, from drugs and needles to equipment, plus maintenance, will be tracked at national level by a newly installed IT system, (already in place and being test run). ${ }^{[1]}$

Instead of hospital budgets being micromanaged by an official in a remote provincial office, Smith said that those on-site managers who showed that they could manage their cheque books would be allowed to do so.

Both he and Lukhele highlighted the systemic problem of 'middlemen' siphoning billions out of the provincial health procurement and maintenance budget. ${ }^{[2]}$ This is due to either unethical practices (Izindaba previously reported on allegations that one company was delivering hospital food consignments to commercial food outlets in Soweto) ${ }^{[3]}$ or simply adding cost to the end consumer price, sometimes even bumping it higher than in the private health sector.

Smith said that between 2003 and 2009, a similar R10 million consultant-run intervention in his surgery department 'made it a much happier place to work', but was shut down after acrimony with junior managers, who seemed to perceive it as a threat to their power. 'We simply went to unbelievable dysfunction in a very short time, so I can see why there's cynicism out there. However, this has a real chance of success if all parties come to the table - I've not seen an offering with as much value as this one', Smith added.

\section{Clinicians 'contemplated legal action'}

Habib told Izindaba that Carter and hospital managers would run the new pilot

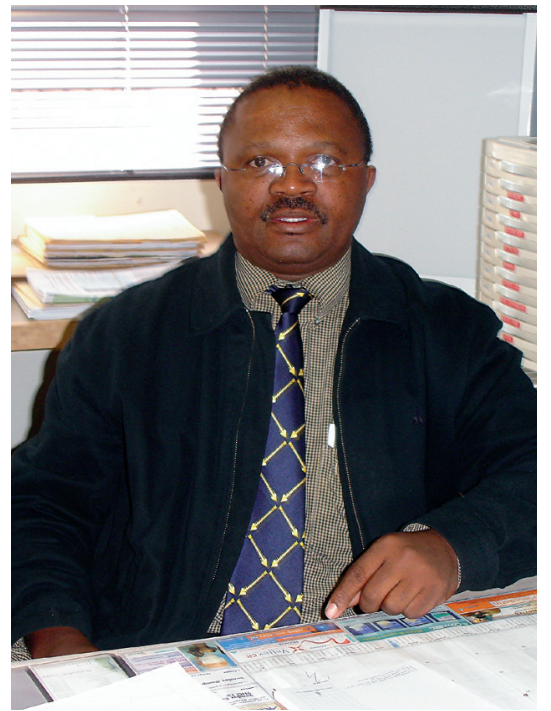

Professor Mac Lukhele, Head of the School of Clinical Medicine at Wits.

programme. His job would be to facilitate 'a pragmatic, transcendent conversation to address these challenges', while acting as a channel to the minister if deadlock was reached on implementing any part of the new system. He conceded that there is 'significant bad blood' between the clinicians, management and the province, with clinicians so frustrated that they have even considered legal action. 'There are already people saying it's not working, but I won't let them use appeal structures if they've not used [the new] internal ones first!' said Habib. 'We have to make it work. I'm not the judge, the minister is. I'm merely the conduit to him.

Habib promised to crack down mercilessly on both clinicians taking advantage of systemic dysfunction to abuse RWOPS and corrupt outside service providers. Habib said, 'If you catch a crook you throw the book at them. Throwing a couple of them in jail will have a far bigger impact than crossing the i's and dotting the t's. Writing policies never resolves corruption.' He said he had told the clinicians that he would not defend anyone in violation of their professional ethics. 'In fact, I told them I would work with government to smoke [violators] out and I wanted them to help me. That will give me the legitimacy I need to defend them against bureaucratic madness and give them what they need to create an enabling environment.

'So often it's a dialogue of the deaf, with government talking about accountability and academics talking about academic freedom. Frankly I believe in both. I'll defend academic freedom, but not the freedom to protect inherited privilege. We need to be accountable to the patient - we can't wish the poor away. We can be responsible to the rich and powerful in our society for their skill set while building a new nation and addressing the historical disparities of our past. They're not mutually exclusive.'

\section{Provincial health systems 'clumsy'}

Lukhele said clinicians and managers have to start talking to each other instead of 'across one another'. 'Unlike higher education, health management is a provincial competence where national government provides strategic direction, but not actual implementation. Health budgets are managed at provincial level with no ring-fencing of funds, making the current federal system clumsy and difficult to manage. Ironically, as in the recent Limpopo medicine stockouts debacle, it is the national minister who shoulders the blame - something that needs looking at,' said Lukhele.

Lukhele said that the new Gauteng tertiary health intervention is 'busy setting up processes, system implementation and time frames. He added, 'There've been plenty of walk-arounds and working committees set up but some of the changes are already concrete and will impact immediately.'

\section{All parties Izindaba interviewed blamed much of the wastage on legitimate or semi-legitimate 'middlemen', who push up prices or actually steal from hospital consignments, including food destined for patients.}

Smith summed up the hopes and aspirations of many of his colleagues: 'This is the first time I've seen something on the table that I think is workable. If we can't get this right I don't know what the solution is for healthcare in this province.'

He could legitimately add, given that it's a national pilot project: 'and the entire country'

\section{Chris Bateman}

chrisb@hmpg.co.za

\footnotetext{
1. Bateman C. Drug stock-outs: Inept supply-chain management and corruption. S Afr Med J 2013;103(9):600-602. [http://dx.doi. org/10.7196/SAMJ.7332]

2. Bateman C. 'Fix the damn system!' - Johannesburg's tertiary hospital doctors. S Afr Med J 2011;101(3):152-156.

Bateman C. Gauteng MEC shifts corruption focus to healthcare workers. S Afr Med J 2010;100(6):340-341.
}

S Afr Med J 2013;103(10):705-706

DOI:10.7196/SAMJ.7469 